Эвиев Валерий Андреевич, доктор технических наук, доцент, профессор кафедры агроинженерии, декан инженерно-технологического факультета Калмыцкого государственного университета имени Б. Б. Городовикова (Республика Калмыкия, г. Элиста, ул. Пушкина, 11). E-mail:aviev@yandex.ru

Беляева Балюта Иренденевна, кандидат педагогических наук, доцент кафедры агроинженерии инженерно-технологического факультета Калмыцкого государственного университета имени Б. Б. Городовикова (Республика Калмыкия, г. Элиста, ул. Пушкина, 11). E-mail: belva67@mail.ru

Кокурин Руслан Геннадьевич, аспирант кафедры «Теплоэнергетика и информационноуправляющие системы», Азово-Черноморского инженерного института ФГБОУ ВО Донской ГАУ (347740, Ростовская область, г. Зерноград, ул. Ленина, д. 21). E-mail: chemistr@yandex.ru

\title{
DOI: 10.32786/2071-9485-2021-02-46 \\ DYNAMICS OF PRECIPITATION AND TEMPERATURE IN THE SUMMER PERIOD ON THE TERRITORY OF THE VOLGOGRAD TRANS-VOLGA REGION
}

\author{
V.G. Yuferev, N.A. Tkachenko, \\ Federal State Budget Scientific Institution \\ «Federal Scientific Centre for Agroecology, Complex Melioration and protective \\ Afforestation of the Russian Academy of Sciences», Volgograd
}

Received 10.02.2021

Submitted 11.05.2021

\begin{abstract}
The work is executed at financial support of the RFBR and the Volgograd oblast in the framework of the scientific project No. 19-45-340003 "Scientific justification and patterns of state change of landscapes ecotone Small Sirt - Caspian lowland in Volgograd Trans-Volga region".
\end{abstract}

Summary

A significant part of the lands of the Volgograd Trans-Volga region, which are in agricultural circulation, is located in the zone of unstable and insufficient moisture. As a result, the determination of the dynamics of precipitation and temperature, the characteristics of their changes are important for the forecast of droughts. Analysis of spatial data on changes in climatic conditions has shown that the dynamics tends to tighten the arid conditions and increase the likelihood of very severe droughts in the Volgograd Trans-Volga region.

Abstract
The relevance of research on the territory of the Volgograd Trans-Volga region is determined by the prolonged absence of precipitation or their significant reduction in comparison with the average longterm norms in unfavorable years, which, in conditions of high temperatures of air masses, the upper layer of soil and prolonged winds, leads to drought, in which the humidity of air and soil sharply decreases, the water balance of vegetation is disturbed, the productivity of agricultural products decreases. Introduction. A significant part of the lands of the Volgograd Trans-Volga region, which are in agricultural circulation, are located in the zone of unstable and insufficient moisture. As a result, the determination of the dynamics of precipitation and temperature, the characteristics of their change are important for the forecast of droughts. Methods and techniques. The analysis of spatial data on changes in climatic conditions was carried out using the methods of geostatistics, as well as geographic information systems for the spatial determination of the average values of the main meteorological quantities for the period 1969-2020. Dynamics studies were carried out in the period from April to October. As a result, changes in the amount of precipitation, the amount of average daily temperatures and changes in the Selyaninov hydrothermal coefficient were established. Results and conclusion. Studies have shown that the dynamics of changes in the amount of precipitation for the period under consideration is determined by the average speed $V_{R}=-1,88 \mathrm{~mm}$ per year and shows a decrease in precipitation in the period under consideration by $96 \mathrm{~mm}$. The dynamics of the sum of average daily temperatures is determined by the average rate $\mathrm{Vt}=0,32 \%$ year and shows an increase in the sum of average daily temperatures in the period under consideration by $16^{\circ}$. The average rate of decrease in Selyaninov's hydrothermal coefficient is 0.001 units per year. For 50 years, on the territory of the Volgograd Trans-Volga region, Selyaninov's hydrothermal coefficient has decreased by 0.05 units. A tendency has been established to toughen arid conditions and the likelihood of very severe droughts on 


\section{***** H3BECTYЯ ***** \\ НИЖНЕВОАЖСКОГО АГРОУНИВЕРСИТЕТСКОГО КОМПАЕКСА: \\ НАУКА И ВЫСШЕЕ ПРОФЕССИОНААЬНОЕ ОБРАЗОВАНИЕ}

the territory of the Volgograd Trans-Volga region. This situation requires the intensification of the complex of reclamation measures from irrigation and forest reclamation of agricultural landscapes to the transfer of land to pastures.

Key words: dynamics, precipitation, temperature, hydrothermal coefficient, climate, conditions, speed, drought.

Citation. Yuferev V. G., Tkachenko N. A. Dynamics of precipitation and temperature in the summer period on the territory of the Volgograd Trans-Volga region. Proc. of the Lower Volga AgroUniversity Comp. 2021. 2(62). 467-475 (in Russian). DOI: 10.32786/2071-9485-2021-02-46.

Author's contribution. The authors of this study collected material, analyzed the data and wrote the paper.

Conflict of interest. The authors declare no conflict of interest.

УДК 633.2(58.02)

\section{ДИНАМИКА ОСАДКОВ И ТЕМПЕРАТУРЫ В ЛЕТНИЙ ПЕРИОД} НА ТЕРРИТОРИИ ВОЛГОГРАДСКОГО ЗАВОЛЖЬЯ

В. Г. Юферев, доктор сельскохозяйственных наук

Н. А. Ткаченко, кандидат сельскохозяйственных наук

Федеральное государственное бюджетное научное учреждение Федеральный научный центр агроэкологии, комплексных мелиорачий и защитного лесоразведения Российской академии наук, г. Волгоград

Дата поступления в редакцию 10.02.2021

Дата принятия к печати 11.05.2021

Работа выполнена при финансовой поддержке РФФИ и Волгоградской области в рамках научного проекта № 19-45-340003 «Научное обоснование и закономерности изменения состояния ландиафтов экотона Малый Сырт - Прикаспийская низменность в Волгоградском Заволжсье»

Актуальность исследований на территории Волгоградского Заволжья определена продолжительным отсутствием осадков или их значительным сокращением по сравнению со средними многолетними нормами в неблагоприятные годы, что в условиях высоких температур воздушных масс верхнего слоя почвы и продолжительных ветров приводит к засухе, при которой резко снижается влажность воздуха и почв, нарушается водный баланс растительности, снижается продуктивность сельскохозяйственной продукции. Значительная часть земель Волгоградского Заволжья, находящихся в сельскохозяйственном обороте, располагается в зоне неустойчивого и недостаточного увлажнения, вследствие чего, определение динамики осадков и температуры, характеристик их изменения имеют значение для прогноза засух. Материалы и методы. Анализ пространственных данных по изменению климатических условий проводился с использованием методов геостатистики, а также геоинформационных систем для пространственного определения средних значений основных метеорологических величин за период 1969-2020 гг. Исследования динамики проведены в период с апреля по октябрь. В результате установлены изменения сумм выпадения осадков, сумм среднесуточных температур и изменения гидротермического коэффициента Селянинова (ГТК). Результаты и обсуждение. Исследования показали, что динамика изменения суммы осадков за рассматриваемый период определяется средней скоростью $\mathrm{V}_{\mathrm{R}}=-1,88$ мм/год и показывает снижение осадков в рассматриваемый период на 96 мм. Динамика суммы среднесуточных температур определяется средней скоростью $\mathrm{Vt}=0,32 \%$ год и показывает повышение суммы среднесуточных температур в рассматриваемый период на $16^{\circ}$. Средняя скорость снижения ГТК составляет 0,001 ед/год. За 50 лет на территории Волгоградского Заволжья ГТК снизился на 0,05 ед. Выводы. Установлена тенденция к ужесточению засушливых условий и вероятности проявления очень сильных засух на территории Волгоградского Заволжья. Такая ситуация требует интенсификации комплекса мелиоративных мероприятий от орошения и лесомелиорации агроландшафтов до перевода угодий в пастбища.

Ключевые слова: динамика осадков, методы геостатистики, суммы выпадения осадков, климатические условия Заволжья. 
Цитирование. Юферев В. Г., Ткаченко Н. А. Динамика осадков и температуры в летний период на территории Волгоградского Заволжья. Известия НВ АУК. 2021. 2(62). 467-475. DOI: $10.32786 / 2071-9485-2021-02-46$.

Авторский вклад. Авторы настоящего исследования собрали материал, проанализировали данные и написали рукопись.

Конфликт интересов. Авторы заявляют об отсутствии конфликта интересов.

Введение. Величина осадков в летний период на территории Волгоградского Заволжья определена особенностями ландшафта, в том числе климатическими условиями, включая циркуляционные процессы в атмосфере. При этом многолетние исследования показали, что засухи наблюдаются на большой площади и наносят значительный ущерб сельскохозяйственному производству, в том числе представляют проблему для животноводства, уменьшая кормовую базу. Засухи не только снижают урожайность сельскохозяйственных культур, но и вызывают гибель посевов на больших площадях, увеличивают вероятность появления болезней и развития сельскохозяйственных вредителей, что способствует деградации растений, возрастанию вероятности возникновения пожаров. Сочетание неблагоприятных последствий изменения климата и деградации земель проявляются в нашей стране в засухах, пыльных бурях и суховеях и др., что отрицательно сказывается на возможностях развития целого ряда отраслей. Для России мониторинг засушливых явлений имеет особую значимость, поскольку значительная часть земель, находящихся в сельскохозяйственном обороте, располагается в зоне неустойчивого и недостаточного увлажнения. К таким территориям относится Волгоградское Заволжье, отличительными чертами которого являются высокая степень засушливости, дефицит влаги, изменчивость погоды, частое проявление сильных и катастрофических засух. Следовательно, изучение динамики осадков и температуры в летний период является актуальной современной проблемой, а изучение пространственных закономерностей и взаимосвязи процессов является важной научной задачей.

Территория Волгоградского Заволжья обладает большим биоклиматическим потенциалом для производства продовольственных и технических культур в России, но в то же время в связи с недостатком атмосферной влаги подвержена засухам $[3,9,10,12]$. Повторяемость сильных атмосферных засух с засушливыми условиями составляет более $80 \%$, поэтому богарное земледелие здесь обусловлено определенным риском, так как частые засухи обусловливают низкую экономическую эффективность производства сельскохозяйственных культур $[8,13]$.

Величина ущерба, наносимого в результате засух, зависит от их интенсивности, времени возникновения и продолжительности, поэтому актуальной проблемой является выявления закономерностей проявления засух $[4-7,11]$. Анализ изменения климатических условий по показателям многолетнего мониторинга на территории Волгоградского Заволжья проводился с использованием геоинформационного моделирования и картографирования на основе архивных данных метеорологических наблюдений и спутниковой информации.

Материалы и методы. Статистический анализ пространственных данных по изменению региональных климатических условий проводился с использованием геоинформационных систем на основе сравнения пространственно определенных средних значений основных метеорологических величин за период 1969-2020 гг., который обусловлен наличием полных данных по метеоусловиям к координатам метеостанций региона исследований. В связи с тем, что современные климатические условия для рассматриваемой территории имеют тенденцию к повышению среднегодовой температуры и одновременно к снижению осадков, для оценки изменения характеристик теплового и влажностного режима агроландшафтов для выбранной территории с апреля по октябрь в период 1969-2020 гг. 
на территории Волгоградского Заволжья проведены исследования изменения суммарной среднесуточной температуры, изменения суммы выпадения осадков и изменения гидротермического коэффициента Селянинова (ГТК). Источником данных был выбран климатический архив ВНИИГМИ-МДЦ [1]. Анализ распределения осадков (рисунок 1), показал, что среднемноголетние осадки в Волгоградском Заволжье распределены от 400 мм в западной части и до 250 мм в восточной с восточным направлением снижения.

В связи с этим динамика определялась по данным репрезентативной метеостанции Палласовка. В целом же рассматривались данные близких по расположению метеостанций Эльтон, Волгоград, Верхний Баскунчак и еще данные 21 станции на территориях, прилегающих к объекту исследований.

Статистический анализ изменения указанных выше параметров проводился на основе сравнения средних значений их величин за период наблюдений 1969-2020 гг., для температуры - сумма среднесуточных температур по месяцам, для осадков - сумма месячных осадков за период апрель - октябрь.

Уровень засушливости устанавливался по гидротермическому коэффициенту Г.Т. Селянинова [2]. Разной степени увлажнения соответствует следующая градация: ГТК < 0,30 - очень сильная засуха, 0,31 $\leq$ ГТК $<0,60$ - сильная засуха, $0,61 \leq \Gamma$ ТК $<0,80$ - средняя засуха, $0,81 \leq \Gamma$ ТК $<1,00$ - слабая засуха, ГТК $>1,00$ - достаточное увлажнение.

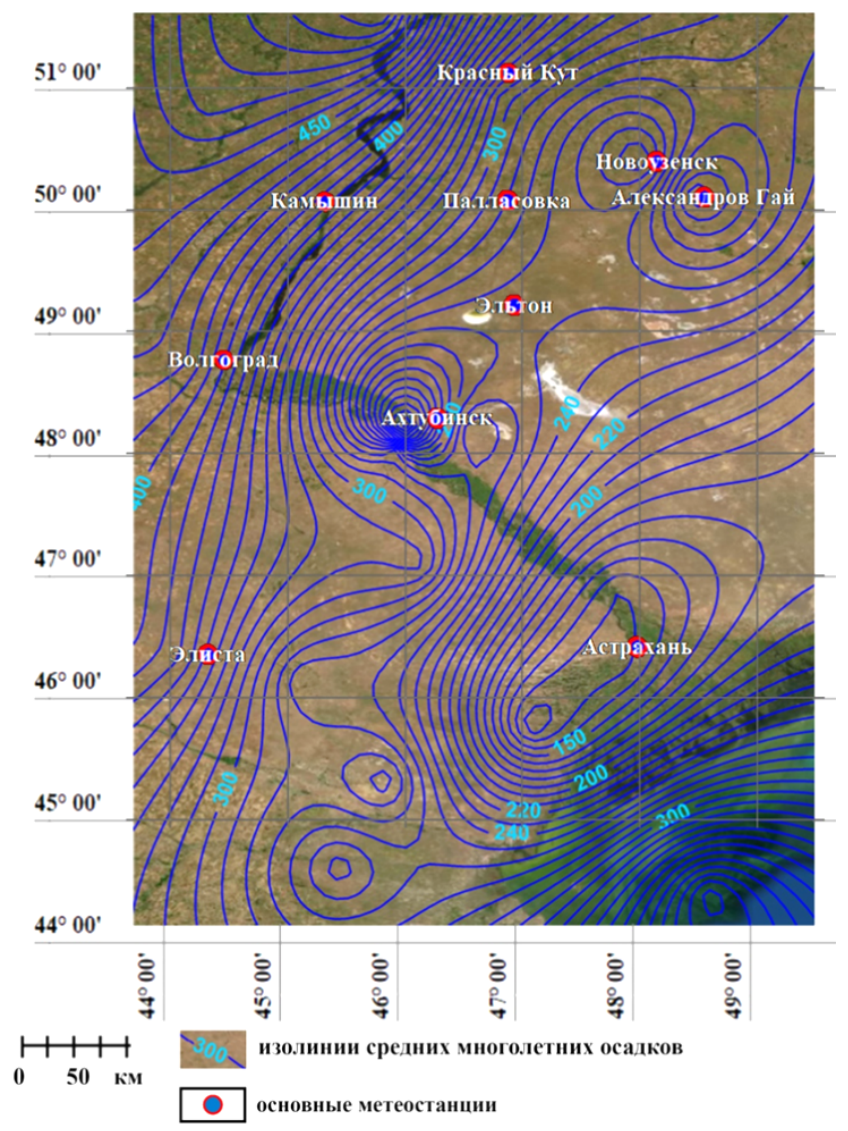

Рисунок 1 - Изолинейная карта осадков на территории исследований

Figure 1 - Isolinear map of precipitation in the territory of the research

Результаты и обсуждение. Анализ изменения среднего многолетнего количества осадков в Волгоградском Заволжье по метеостанции Палласовка (рисунок 2) показал, что его территория расположена в зоне недостаточного увлажнения. Максимум отмечен в 1993 и составил 425 мм, минимальное значение - 46 мм - в 2006 году. 
Статистический анализ осадков за 50 лет показал доверительный интервал изменения количества осадков с вероятностью $95 \%-211,2 \pm 28,0$ мм. Вероятный уровень осадков показывает в целом наличие засушливых условий на территории исследований. Линейный тренд изменения количества осадков за 50-летний период может быть представлен уравнением регрессии $\mathrm{R}=-1,88 \mathrm{x}+256,9$, где $\mathrm{x}$ - год от начала наблюдений. Динамика изменения суммы осадков за рассматриваемый период определяется средней скоростью, в соответствии с первой производной по уравнению регрессии составляет $\mathrm{V}_{\mathrm{R}}=-1,88 \mathrm{mм} /$ год и показывает снижение осадков в рассматриваемый период на 96 мм.

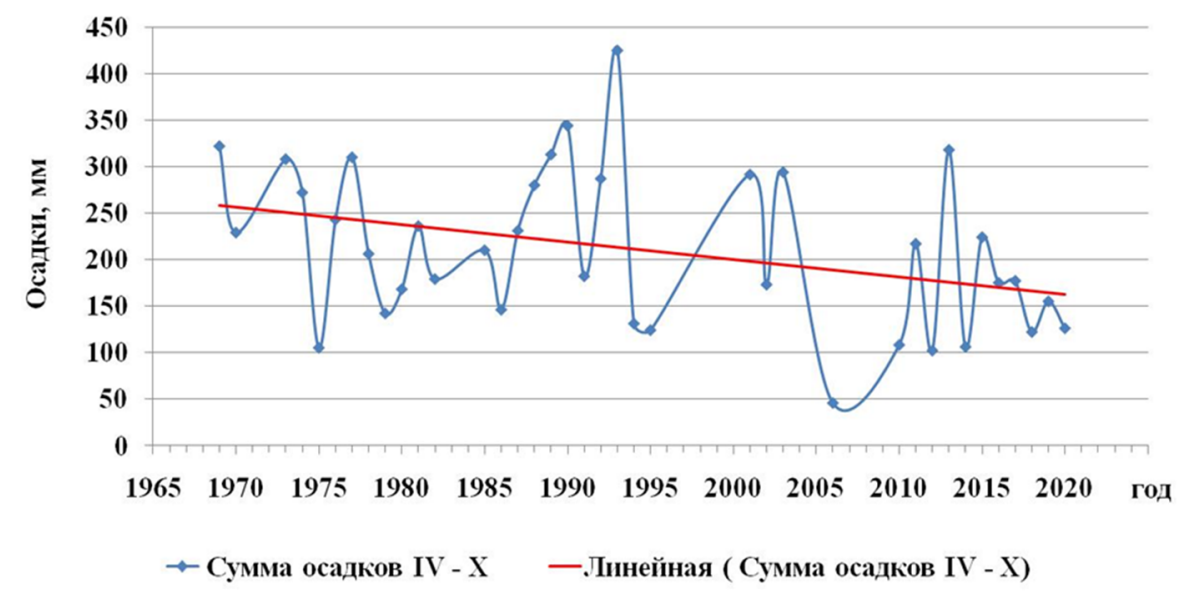

Рисунок 2 - Изменение количества осадков на территории исследований

Figure 2 - Changes in precipitation in the territory of the research

Анализ изменения суммы среднесуточных температур (рисунок 3 ) показал доверительный интервал $115,1 \pm 2,74^{\circ}$, то есть разброс температур за период наблюдений с вероятностью $95 \%$ укладывается в интервал $5,48^{\circ}$ от среднего, а многолетний линейный тренд может быть представлен уравнением регрессии tсрс $=0,32 \mathrm{x}+107,2$, где $\mathrm{x}-$ год от начала наблюдений.

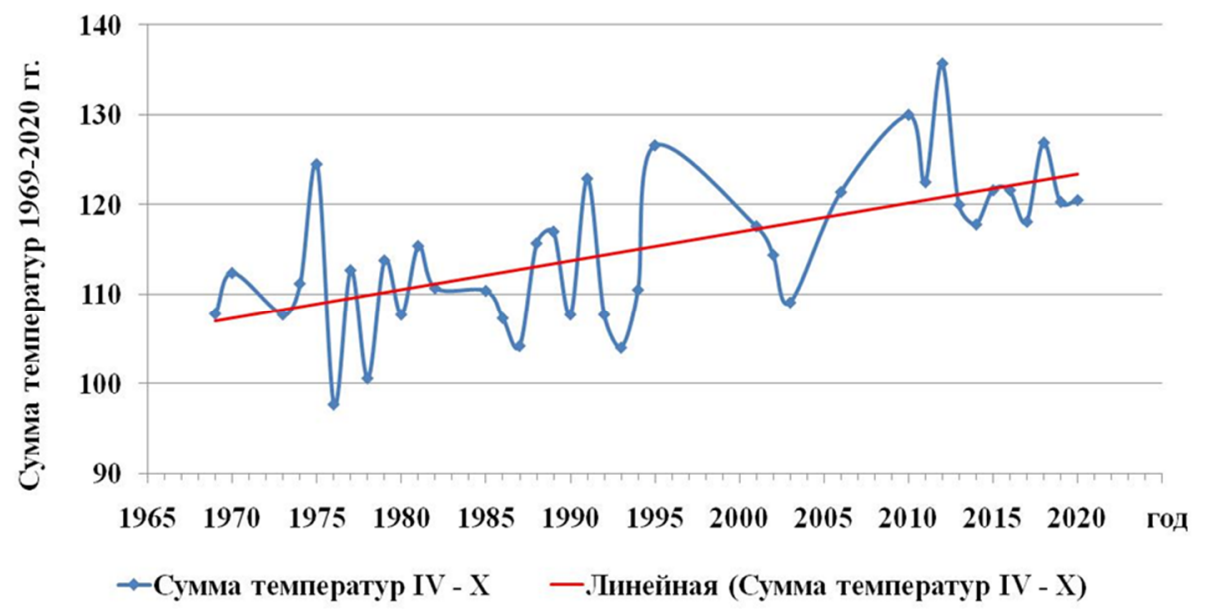

Рисунок 3 - Изменение суммы среднесуточных температур на территории исследований

Figure 3-Change in the sum of the average daily temperatures in the territory of the research

Динамика суммы среднесуточных температур за рассматриваемый период определяется средней скоростью, которая в соответствии с первой производной по уравнению регрессии, составляет $\mathrm{Vt}=0,32$ \%год и показывает повышение суммы среднесуточных температур в рассматриваемый период на $16^{\circ}$. 
Анализ изменения гидротермического коэффициента (рисунок 4) показал, что этот коэффициент практически полностью повторяет изменение суммарного количества осадков (рисунок 2).

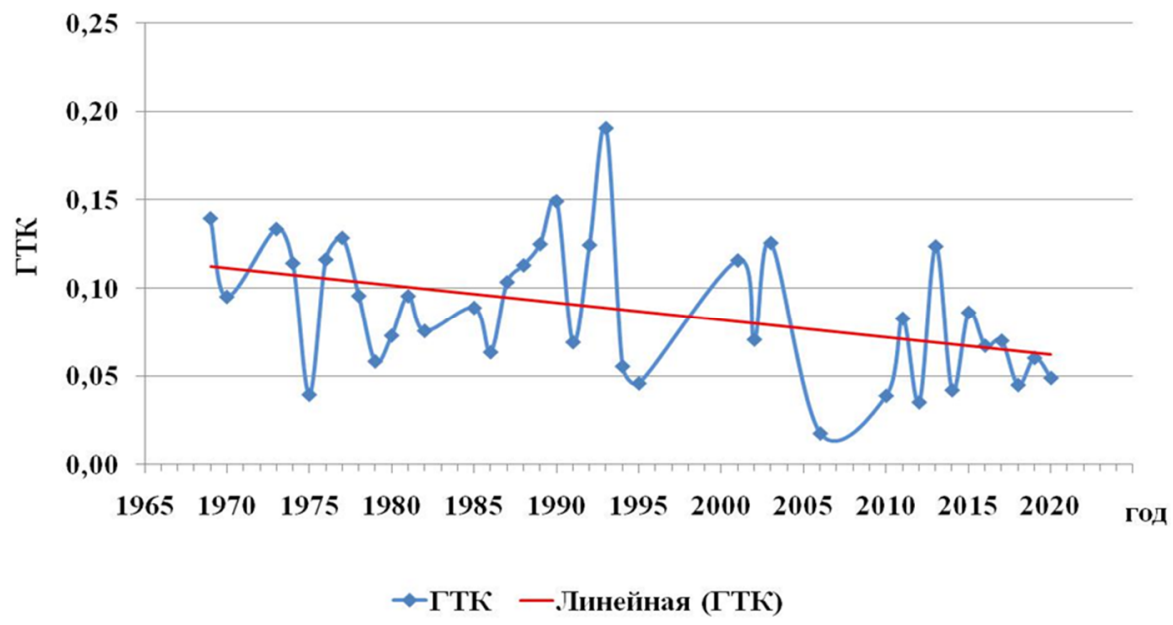

Рисунок 4 - Изменение ГТК на территории исследований

Figure 4-Change in the hydrothermal coefficient in the territory of the research

Корреляционный анализ (таблица 1) также показал сильную связь суммы осадков за рассматриваемый период и ГТК $(0,990)$, и среднюю обратную для суммы среднесуточных температур и ГТК $(-0,634)$. Связь между изменением суммы осадков за рассматриваемый период и суммы среднесуточных температур - средняя обратная $(-0,537)$.

Таблица 1 - Коэффициенты корреляции рядов данных ГТК, суммы среднесуточных температур и суммы осадков

Table 1-Correlation coefficients of the series data of the hydrothermal coefficient, the sum of the average daily temperatures and the sum of precipitation

\begin{tabular}{|c|c|c|c|}
\hline & $\begin{array}{c}\text { ГТК } \\
\text { Hydrothermal } \\
\text { coefficient }\end{array}$ & $\begin{array}{c}\text { Сумма температур } \\
\text { Sum of the average daily } \\
\text { temperatures }\end{array}$ & $\begin{array}{c}\text { Сумма осадков } \\
\text { Sum of precipitation }\end{array}$ \\
\hline $\begin{array}{c}\text { ГТК } \\
\text { Hydrothermal coefficient }\end{array}$ & 1 & & \\
\hline $\begin{array}{c}\text { Cyмma температур } \\
\text { Sum of the average daily } \\
\text { temperatures }\end{array}$ & $-0,634$ & 1 & 1 \\
\hline $\begin{array}{c}\text { Cумма осадков } \\
\text { Sum of precipitation }\end{array}$ & 0,990 & $-0,537$ & \\
\hline
\end{tabular}

Доверительный интервал ГТК равен $0,087 \pm 0,013$, он показывает, что с 95 \% вероятностью этот коэффициент будет в интервале $0,1-0,074$, что соответствует очень сильной засухе.

Многолетний линейный тренд изменения ГТК может быть представлен уравнением регрессии ГТК $=-0,001 \mathrm{x}+0,1114$, где $\mathrm{x}-$ год от начала наблюдений.

Исходя из этого уравнения средняя скорость снижения ГТК составляет 0,001 ед/год. За 50 лет на территории Волгоградского Заволжья ГТК снизился на 0,05 ед.

Выводы. В результате исследований установлена средняя скорость изменения суммарного количества осадков с апреля по октябрь за 50-летний период исследований, составляющая $\mathrm{V}_{\mathrm{R}}=-1,88 \mathrm{Mм} /$ год, и показывает снижение осадков в рассматриваемый период на 96 мм, средняя скорость изменения суммы среднесуточных температур $\mathrm{Vt}=0,32$ \% год, 
что показывает повышение суммы среднесуточных температур в рассматриваемый период на $16^{\circ}$. Изменение ГТК также имеет тенденцию к снижению скорость которого составляет 0,001 ед/год. За 50 лет на территории Волгоградского Заволжья ГТК снизился на 0,05 ед. Таким образом, установлена тенденция к ужесточению засушливых условий и вероятности проявления очень сильных засух на территории Волгоградского Заволжья. Такая ситуация требует интенсификации комплекса мелиоративных мероприятий от орошения и лесомелиорации агроландшафтов до перевода угодий в пастбища.

\section{Библиографический список}

1. Архив климатических данных ВНИИГМИ-МЦЦ. http://meteo.ru/.

2. Виноградова В. В. Тепловое воздействие на территории России в середине XXI века по модельным данным // Известия Российской академии наук. Серия географическая. 2020. № 3. С. $403-413$.

3. Глобальный климат и почвенный покров России: опустынивание и деградация земель, институциональные, инфраструктурные, технологические меры адаптации (сельское и лесное хозяйство): Национальный доклад / под ред. Р. С.-Х. Эдельгериева. М.: ООО «Издательство МБА», 2019. Т. 2. 476 с.

4. Золотокрылин А. Н. Засухи и опустынивание в суббореальных ландшафтах России // Известия РАН. Сер. Географическая. 2013. № 5. С. 64-73.

5. Золотокрылин А. Н., Черенкова Е. А., Титкова Т. Б. Аридизация засушливых земель Европейской части России и связь с засухами // Известия Российской академии наук. Серия географическая. 2020. № 2. С. 207-217.

6. Лысенко С. А. Климатообусловленные изменения биопродуктивности наземных экосистем Беларуси // Исследование земли из космоса. 2019. № 6. С. 77-88.

7. Переведенцев Ю. П., Шарипова Р. Б., Важнова Н. А. Агроклиматические ресурсы Ульяновской области и их влияние на урожайность зерновых культур // Вестник Удмуртского университета. 2012. Вып. 2. С. 120-126.

8. Рубан Д. А., Яшалова Н. Н. Опасность засухи как вызов для сельского хозяйства россии в современных экономических условиях // Национальные интересы: приоритеты и безопасность. 2017. № 2. С. 101-113.

9. Climate Change 2013: The Physical Science Basis. Contribution of Working Group I to the Fifth Assessment Report of the Intergovernmental Panel on Climate Change / T. F. Stocker, D. Qin, G.-K. Plattner [et al.]. Cambridge: Cambridge University Press, 2013. 2535 p.

10. Crucial role of Black Sea warming in amplifying the 2012 Krymsk precipitation extreme / E. P. Meredith [et al.] // Nature Geoscience. 2015. Vol. 8. P. 615-619.

11. Estimation of drought-related yield loss using the dynamic statistical model of crop productivity forecasting / A. D. Kleshchenko [et al.] // Russian Meteorology and Hydrology. 2016. V. 41. № 4. P. 299-306.

12. Geoinformational analysis of desertification of the northwestern caspian / K. N. Kulik, V. I. Petrov, V. G. Yuferev, N. A. Tkachenko, S. S. Shinkarenko // Arid Ecosystems. 2020. V. 10. № 2. P. 98-105.

13. Peterson T. C. Climate change indices // WMO Bulletin. 2005. Vol. 54. No. 2. P. 83-86.

Conclusions. The research found the average rate of change of the total precipitation from April to October, the 50-year period of research, component VR $=-1,88 \mathrm{~mm} / \mathrm{year}$ and shows a decrease in precipitation in the period under review, $96 \mathrm{~mm}$, the average rate of change of the sum of average daily temperatures $\mathrm{Vt}=0,32 \square /$ year, which indicates an increase in the amount of average daily temperatures in the period under review, 16 $\square$. The change in the SCC also tends to decrease, the rate of which is 0.001 units / year. For 50 years in the territory of the Volgograd Zavolzhye, the SCC decreased by 0.05 units. Thus, there is a tendency to increase the severity of dry conditions and the likelihood of very severe droughts 
in the Volgograd Trans-Volga region. This situation requires the intensification of the complex of land reclamation measures from irrigation and forest reclamation of agricultural landscapes to the transfer of land to pastures.

\section{References}

1. Arhiv klimaticheskih dannyh VNIIGMI-MCC. http://meteo.ru/.

2. Vinogradova V. V. Teplovoe vozdejstvie na territorii Rossii v seredine XXI veka po model'nym dannym // Izvestiya Rossijskoj akademii nauk. Seriya geograficheskaya. 2020. № 3. S. 403-413.

3. Global'nyj klimat i pochvennyj pokrov Rossii: opustynivanie i degradaciya ze-mel', institucional'nye, infrastrukturnye, tehnologicheskie mery adaptacii (sel'skoe i lesnoe hozyajstvo): Nacional'nyj doklad / pod red. R. S. -- H. \}del'gerieva. M.: OOO "Izdatel'stvo MBA", 2019. T. 2. 476 s.

4. Zolotokrylin A. N. Zasuhi i opustynivanie v subboreal'nyh landshaftah Rossii // Izvestiya RAN. Ser. Geograficheskaya. 2013. № 5. S. 64-73.

5. Zolotokrylin A. N., Cherenkova E. A., Titkova T. B. Aridizaciya zasushlivyh zemel' Evropejskoj chasti Rossii i svyaz' s zasuhami // Izvestiya Rossijskoj akademii nauk. Seriya geograficheskaya. 2020. № 2. S. 207-217.

6. Lysenko S. A. Klimatoobuslovlennye izmeneniya bioproduktivnosti nazemnyh ]kosistem Belarusi // Issledovanie zemli iz kosmosa. 2019. № 6. S. 77-88.

7. Perevedencev Yu. P., Sharipova R. B., Vazhnova N. A. Agroklimaticheskie resursy Ul'yanovskoj oblasti i ih vliyanie na urozhajnost' zernovyh kul'tur // Vestnik Udmurtskogo universiteta. 2012. Vyp. 2. S. 120-126.

8. Ruban D. A., Yashalova N. N. Opasnost' zasuhi kak vyzov dlya sel'skogo hozyajstva rossii v sovremennyh ]konomicheskih usloviyah // Nacional'nye interesy: prioritety i bezopasnost'. 2017. № 2. S. 101-113.

9. Climate Change 2013: The Physical Science Basis. Contribution of Working Group I to the Fifth Assessment Report of the Intergovernmental Panel on Climate Change / T. F. Stocker, D. Qin, G.-K. Plattner [et al.]. Cambridge: Cambridge University Press, 2013. 2535 p.

10. Crucial role of Black Sea warming in amplifying the 2012 Krymsk precipitation extreme / E. P. Meredith [et al.] // Nature Geoscience. 2015. Vol. 8. P. 615-619.

11. Estimation of drought-related yield loss using the dynamic statistical model of crop productivity forecasting / A. D. Kleshchenko [et al.] // Russian Meteorology and Hydrology. 2016. V. 41. № 4. P. 299-306.

12. Geoinformational analysis of desertification of the northwestern caspian / K. N. Kulik, V. I. Petrov, V. G. Yuferev, N. A. Tkachenko, S. S. Shinkarenko // Arid Ecosystems. 2020. V. 10. № 2. P. 98-105.

13. Peterson T. C. Climate change indices // WMO Bulletin. 2005. Vol. 54. No. 2. P. 83-86.

\section{Authors Information}

Yuferev Valery Grigoryevich, Chief Researcher - Head of the Laboratory of Geoinformation Modeling and Mapping of Agroforestscapes, Federal Research Center of Agroecology of the Russian Academy of Sciences (97 Universitetskiy Ave., Volgograd, 400062, Russian Federation), Doctor of of Agricultural Sciences, tel. 8 (8442) 46-25-86, e-mail: yuferevv@vfanc.ru

Tkachenko Natalia Aleksandrovna, Researcher Laboratory of Geoinformation Modeling and Mapping of Agroforestscapes Researcher, Federal Research Center of Agroecology of the Russian Academy of Sciences (97 Universitetskiy Ave., Volgograd, 400062, Russian Federation), Candidate of of Agricultural Sciences, tel. 8 (8442) 46-25-86, e-mail: tkachenkon@vfanc.ru

\section{Информация об авторах}

Юферев Валерий Григорьевич, главный научный сотрудник - заведующий лабораторией геоинформационного моделирования и картографирования агролесоландшафтов, ФНЦ агроэкологии РАН (РФ, 400062, г. Волгоград, пр-т Университетский, 97), доктор сельскохозяйственных наук, тел. 8 (8442) 46-25-86, e-mail: yuferevv@vfanc.ru

Ткаченко Наталья Александровна, научный сотрудник лаборатории геоинформационного моделирования и картографирования агролесоландшафтов, ФНЦ агроэкологии РАН (РФ, 400062, г. Волгоград, пр-т Университетский, 97), кандидат сельскохозяйственных наук, тел. 8 (8442) 46-25-86, еmail: tkachenkon@vfanc.ru 